\title{
Novel Planar Horn Antenna for 75/85 GHz Experimental Wireless Link
}

\author{
Jan PUSKELY $Y^{1}$, Tomas URBANEC ${ }^{1}$, Tomas MIKULASEK ${ }^{1}$, Zbynek RAIDA ${ }^{1}$, \\ Vaclav RERICHA ${ }^{2}$, Jan BARTYZAL ${ }^{2}$ \\ ${ }^{1}$ Dept. of Radio Electronics, Brno University of Technology, Technicka 12, 61600 Brno, Czech Republic \\ ${ }^{2}$ Tesla a. s., Poděbradská 56/186, 18066 Praha 9, Czech Republic
}

\{puskely, urbanec, mikulasekt, raida\}@feec.vutbr.cz, \{bartyzal.jan, rericha.vaclav\}@tesla.cz

\begin{abstract}
In the paper, we describe a novel H-plane horn antenna for an experimental wireless link operating in frequency bands 71 to $76 \mathrm{GHz}$ and 81 to $86 \mathrm{GHz}$. The horn antenna was designed considering a substrate integrated waveguide (SIW) technology, The waveguide WR12 was used as a feeder. In order to improve transition between a thin-substrate SIW horn antenna and the air, we combined two approaches; a printed transition and a dielectric load. That way, a better impedance matching and better radiation properties were reached. In comparison with other planar horn antennas, we obtained a more directional radiation pattern with more than $5 \mathrm{~dB}$ higher gain and sufficient side lobe suppression in the E-plane. The novel planar H-plane horn antenna was compared with a designed conventional metallic horn antenna.
\end{abstract}

\section{Keywords}

H-plane horn antenna, SIW technology, conventional metallic horn antenna, millimeter waves, wireless experimental link

\section{Introduction}

Today's communication systems face growing requirements of data bandwidth. A high resolution videobased telephony and multimedia services into mobile communication can be given as an example of such a wideband application. This has led to much higher data rate requirements for high speed short-range radio links. Recently the 71-76 GHz and $81-86 \mathrm{GHz}$ frequency slots have been allocated world-wide for wireless applications. Due to the reduced atmospheric attenuation within the licensed $75 / 85 \mathrm{GHz}$ bands as compared to the unlicensed 57-64 GHz region, these bands are preferable for short to medium-range wireless systems. Such typical communication scenario calls for high gain and wideband antennas to be able to receive/transmit complex signal comprising a huge number of different information in both frequency bands. Horn antennas have a good potential for this application. These antennas have a high gain, a wide bandwidth, a high efficiency and a compact structure [1].
We were aimed to design the horn antenna considering a substrate integrated waveguide (SIW) technology and a waveguide WR12 as feeder. When designing a planar Hplane horn antenna using SIW technology we have to take into account an unwanted radiation and a poor matching caused by a substrate of thicknesses $h$ smaller than $\lambda / 6$. On the other hand, the thicker substrates $(h>2.5 \mathrm{~mm})$ are not suitable for manufacturing SIW technology because the via-hole metallization is then challenging. Since the used frequency band, in which the antenna is designed, is in the millimeter-wave region we can easily fulfill both conditions. Another problem of planar SIW horns comprises the matching between the edge of the dielectric slab and the air which decreases the operational bandwidth. Several strategies have been developed to overcome this problem; nonprinted elements [2-4], integrated dielectric lenses [5], or printed transition on the same dielectric slab as the antenna [6].

In this paper, we describe a novel planar horn antenna which combines two approaches - a printed transition introduced in [6] and a dielectric load [3]. That way, the matching between the thin-substrate SIW horn antenna and the air has been improved. The printed transition is etched directly on the dielectric load. Due to the combination of both approaches we have obtained a more directional radiation pattern with a higher gain. The H-plane SIW horn

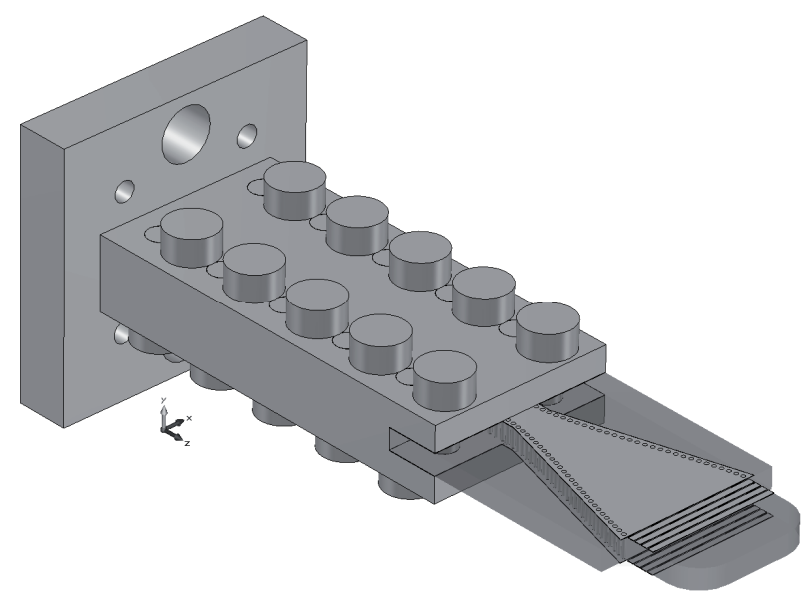

Fig. 1. Novel H-plane SIW horn antenna with the transition to WR12 waveguide as feeder. 
with the proposed transition is represented in Fig. 1. The novel planar H-plane horn antenna was compared with a designed conventional metallic horn antenna. Both horn antennas will be used in experimental wireless link $75 / 85 \mathrm{GHz}$ based on the converter FC1003E/03 produced by Sivers IMA [7].

\section{Novel Horn Antenna for Millimeter Wave Experimental Link}

When we design a planar H-plane horn antenna we have matched a thin-substrate to the air by combining two approaches known - a printed transition introduced in [6], and a dielectric load [3]. That way, we have obtained better radiation patterns with a higher gain.

The antenna structure is depicted in Fig. 2. The antenna was designed for a substrate of the thickness $t_{s}=$ $1.524 \mathrm{~mm}$, the dielectric constant $\varepsilon_{\mathrm{r}}=2.33$ and $\tan \delta=$ 0.009. Shape of the horn antenna is implemented using vias. The separation between vias and the diameter of vias were chosen to be $0.55 \mathrm{~mm}$ and $0.3 \mathrm{~mm}$, respectively, to keep the radiation losses reasonably low. The SIW horn is fed by a waveguide (left side in Fig. 2). At the aperture (right side in Fig. 2), a special transition improves the matching between the antenna and the air. The transition consists of a 4 blocks of metallic plates and a dielectric load in shape of semi-circle.

The antenna is of overall dimensions of approximately $14.0 \times 30.0 \times 1.6 \mathrm{~mm}^{3}$ (width $\times$ length $\times$ height) Numerical values of parameters in Fig. 2: $l_{1}=3.65 \mathrm{~mm}$, $l_{2}=14.82 \mathrm{~mm}, \quad l_{3}=6.00 \mathrm{~mm}, \quad w_{1}=2.25 \mathrm{~mm}, \quad w_{2}=$ $10.00 \mathrm{~mm}, w_{3}=14.10 \mathrm{~mm}, l_{t}=2.20 \mathrm{~mm}, t=0.45 \mathrm{~mm}, s=$ $0.11 \mathrm{~mm}$ and radius of blending $r$ is R2.5.

In order to supply the antenna by power, we used waveguide WR12 $\left(3.10 \times 1.55 \mathrm{~mm}^{2}\right)$ corresponding to the frequency band from $71 \mathrm{GHz}$ to $86 \mathrm{GHz}$. Therefore, the transition between the equivalent SIW waveguide and the WR12 waveguide had to be designed. The transition contains an impedance transformer and a short section of the dielectric filled waveguide which is equivalent to the

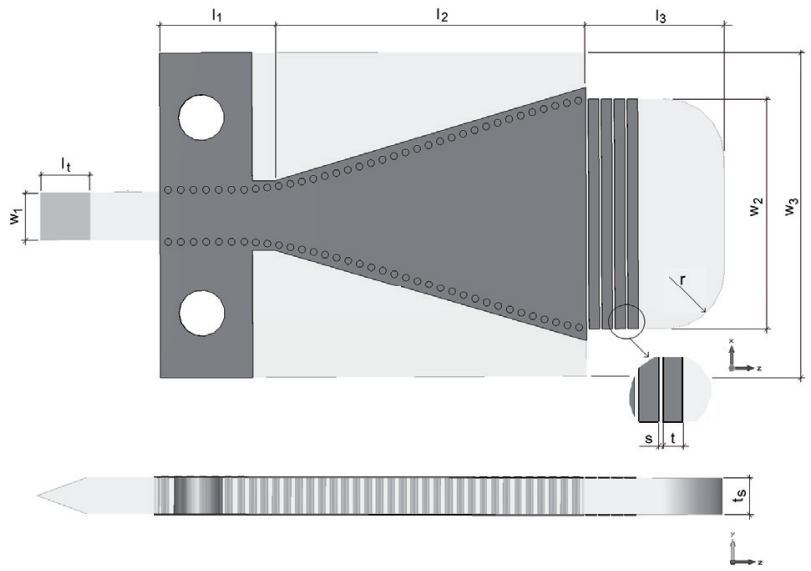

Fig. 2. Designed H-plane SIW horn antenna.

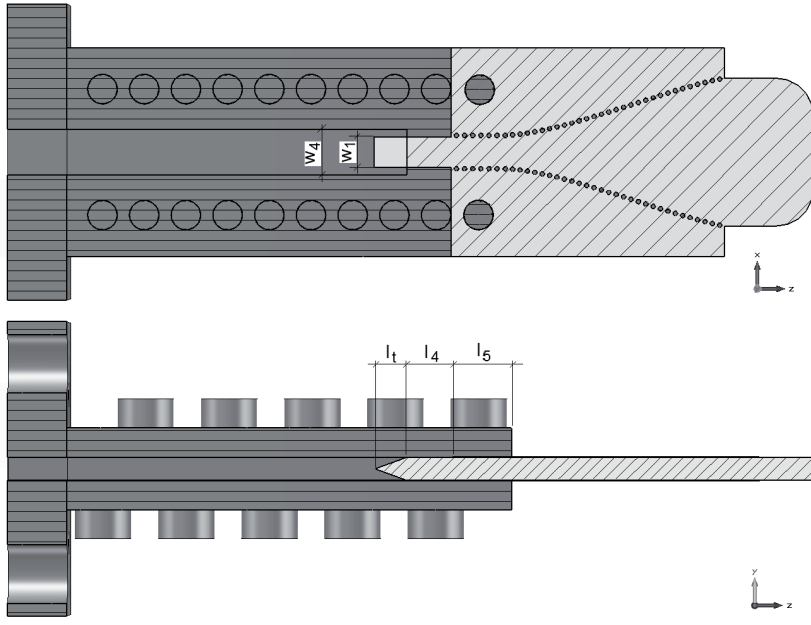

Fig. 3. The transition between the H-plane SIW horn antenna and waveguide WR12.

SIW [8]. Figure 3 shows cuts of this transition. Numerical values of parameters in Fig. 3 are following: $l_{4}=3.00 \mathrm{~mm}$, $l_{5}=4.00 \mathrm{~mm}, w_{4}=3.10 \mathrm{~mm}$.

Planar H-plane horn antenna was modeled and its dimensions were optimized in CST Microwave Studio to cover both the bands of operation.

\subsection{Antenna Parametric Study}

In this section we have studied the influence of both approaches (a printed transition and a dielectric load) solving the problem of matching between a thin-substrate horn antenna and the air. SIW horn antenna was analyzed without transition between the antenna and waveguide WR12.

Firstly we analyzed the different length of dielectric load $l_{3}$. Obtained results (impedance matching and radiation patterns at $73.5 \mathrm{GHz}$ and $83.5 \mathrm{GHz}$ ) are shown in Fig. 4 and Fig. 5, respectively. From impedance matching view point, antenna with a dielectric load exhibits always better properties than without a load. The best impedance matching was obtained when the length of load was $l_{3}=$ $3.00 \mathrm{~mm}$. Further from radiation patterns, the directivity grows with the increasing length of the dielectric load but the level of side lobes grows, too. Obviously from both view points we have chosen the compromise and finally the length of the dielectric load was chosen $l_{3}=6.00 \mathrm{~mm}$.

In the second case we assumed the different numbers of rings and studied their influence on antenna characteristics. The length of dielectric load was chosen $l_{3}=6.00 \mathrm{~mm}$. Dependences of impedance matching and radiation patterns on the number of the metallic plates are shown in Fig. 6 and Fig. 7, respectively.

By this parametric study, we found out that even one metallic plate improves the impedance matching significantly. The metallic plates affect also radiation patterns of the antenna. They improve a little bit the directivity of antenna about $1 \mathrm{dBi}$, decrease the side lobe level and improve front-back ratio, see Figure 7 . The best radiation 


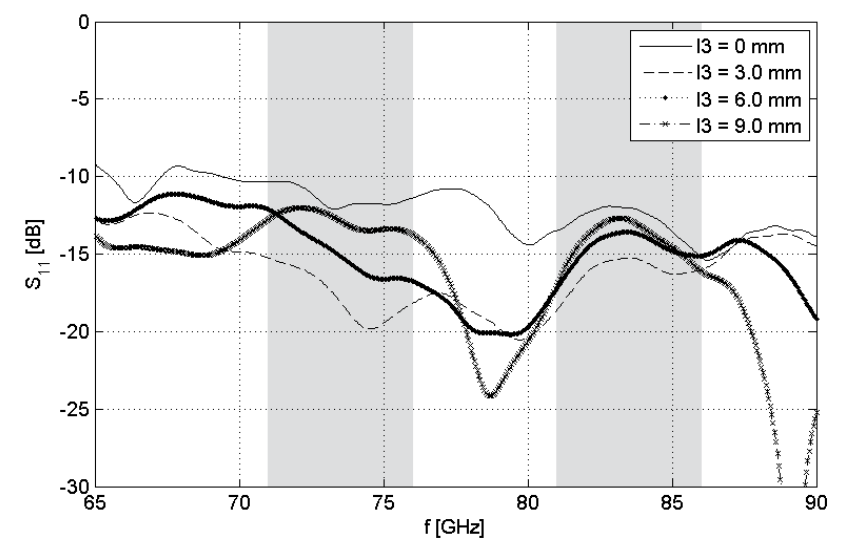

Fig. 4. Reflection coefficient of the antenna in the dependency on the length of the dielectric load.
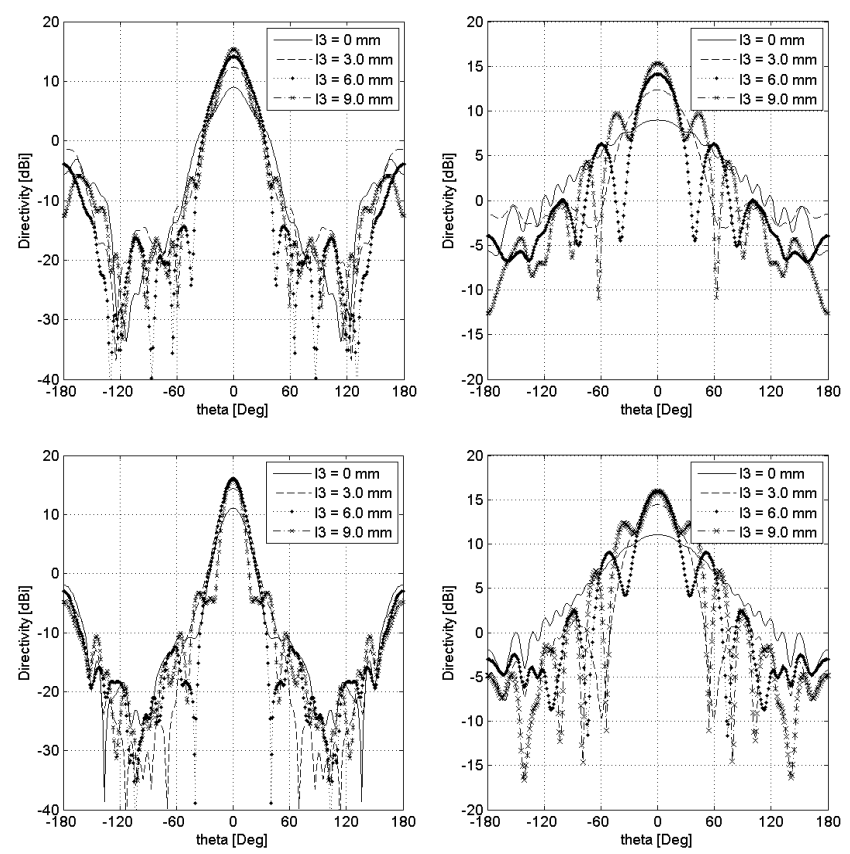

Fig. 5. Radiation patterns of the antenna in the dependency on to the length of the dielectric load; top: $f=73.5 \mathrm{GHz}$; bottom: $83.5 \mathrm{GHz}$; left: H-plane; right: E-plane.

characteristics were obtained when the antenna has four metallic plates.

So, thanks to combination of the printed transition and the dielectric load we obtained better impedance properties and more directional radiation patterns. The novel transition increased the directivity of the antenna (about 5 to $6 \mathrm{dBi}$ ), decreased the side lobe level and improved the front-to-back ratio in both the frequency bands (see Fig. 5 and 7). Directivity of the antenna ranges from $15.1 \mathrm{dBi}$ to $16.4 \mathrm{dBi}$. The level of side lobes (SLL) is better than $12.1 \mathrm{~dB}$ in the E-plane and $22.9 \mathrm{~dB}$ in the H-plane. Frontto-back ratio (FTBR) is better than $27.9 \mathrm{~dB}$ in the whole frequency range.

Radiation properties of the planar SIW horn antenna without and with the novel transition are summarized in Tab. 1.

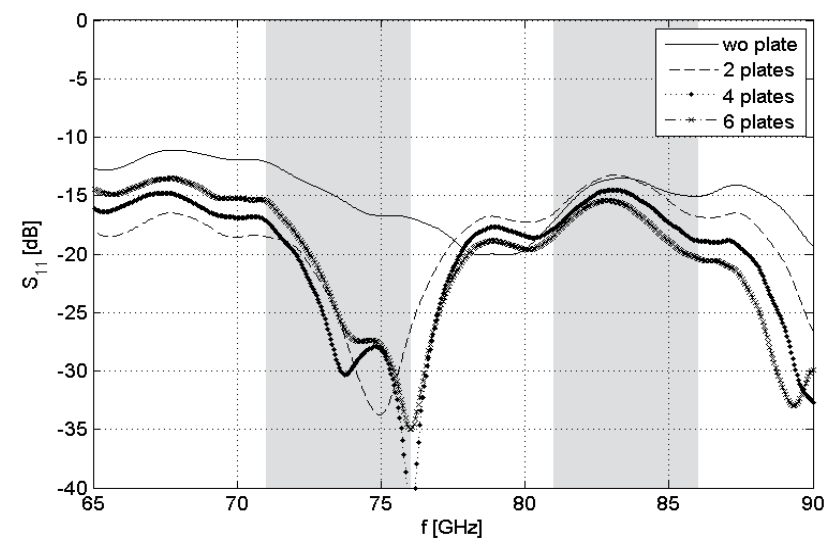

Fig. 6. Reflection coefficient of the antenna in the dependency on the number of metallic plates.
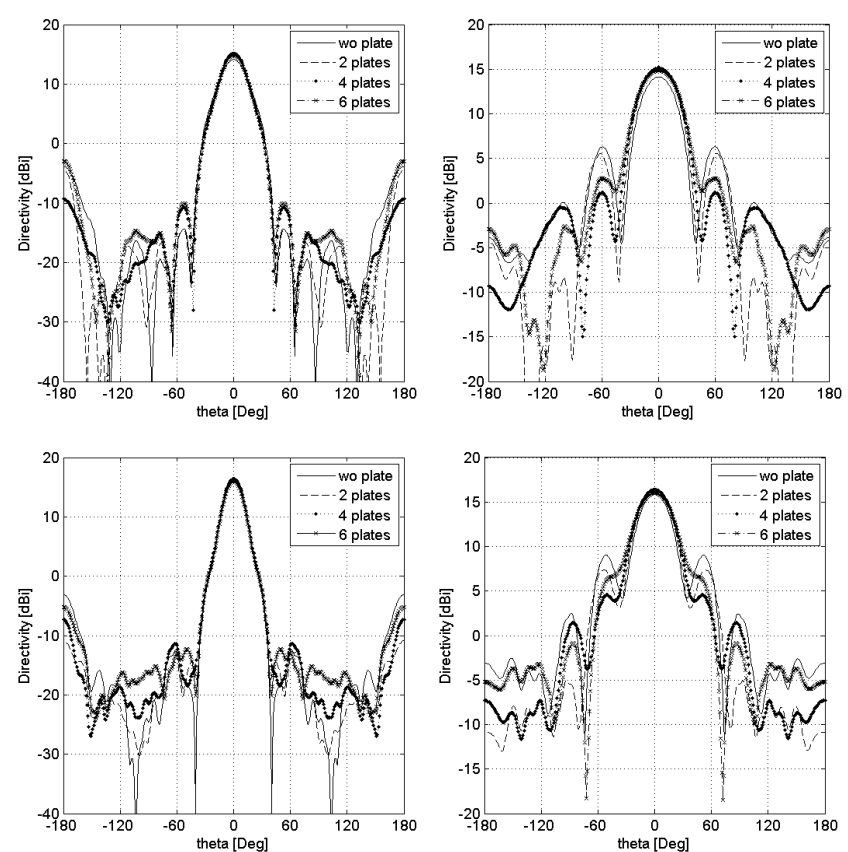

Fig. 7. Radiation pattern of the antenna in the dependency on the number of metallic plates; top: $f=73.5 \mathrm{GHz}$; bottom: $83.5 \mathrm{GHz}$; left: H-plane; right: E-plane.

\begin{tabular}{c|c|c|c|c}
\hline \multicolumn{2}{c|}{ Frequency (GHz) } & $\mathbf{7 1 . 0}$ & $\mathbf{7 3 . 5}$ & $\mathbf{7 6 . 0}$ \\
\hline \hline \multicolumn{2}{c|}{ Directivity (dBi) } & $8.9 / 15.1$ & $10.3 / 15.4$ & $10.5 / 15.9$ \\
\hline \multirow{2}{*}{ SLL (dB) } & plane E & $-/ 13.7$ & $-/ 12.1$ & $-/ 12.1$ \\
\cline { 2 - 5 } & plane H & $16.5 / 23.1$ & $19.0 / 25.1$ & $12.4 / 24.6$ \\
\hline \multirow{2}{*}{ BW (deg) } & plane E & $95.3 / 44.2$ & $90.1 / 43.2$ & $103.3 / 41.5$ \\
\cline { 2 - 5 } & plane H & $31.9 / 23.8$ & $27.5 / 22.9$ & $23.0 / 20.9$ \\
\hline \multicolumn{2}{c}{ FTBR (dB) } & $20.2 / 28.4$ & $20.5 / 27.9$ & $20.6 / 29.7$ \\
\hline \multirow{2}{*}{ Frequency (GHz) } & $\mathbf{8 1 . 0}$ & $\mathbf{8 3 . 5}$ & $\mathbf{8 6 . 0}$ \\
\hline \hline \multicolumn{2}{c|}{ Directivity (dBi) } & $11.1 / 16.3$ & $10.4 / 16.1$ & $11.1 / 16.4$ \\
\hline \multirow{2}{*}{ SLL (dB) } & plane E & $-/ 15.1$ & $-/ 14.5$ & $-/ 13.3$ \\
\cline { 2 - 5 } & plane H & $19.8 / 24.8$ & $20.2 / 22.9$ & $20.1 / 24.6$ \\
\hline \multirow{2}{*}{ BW (deg) } & plane E & $83.0 / 40.7$ & $92.7 / 39.2$ & $82.3 / 38.2$ \\
\cline { 2 - 5 } & plane H & $24.2 / 18.2$ & $23.8 / 18.1$ & $28.6 / 17.3$ \\
\hline \multicolumn{2}{c}{ FTBR (dB) } & $19.7 / 32.8$ & $20.2 / 30.2$ & $20.1 / 28.3$ \\
\hline
\end{tabular}

Tab. 1. Radiation properties of planar SIW horn antenna without the transition/with transition (SLL = side lobe level, $\mathrm{BW}=$ beam width, FTBR = front to back ratio). 


\subsection{Prototyped H-plane Horn Antenna and Experimental Results}

The H-plane horn antenna was designed and fabricated to operate in an experimental wireless link in frequency bands 71 to $76 \mathrm{GHz}$ and 81 to $86 \mathrm{GHz}$. It was printed on a $1.524 \mathrm{~mm}$ thick substrate with a dielectric constant of 2.33 and a loss tangent of 0.0009 (0.004 at $80 \mathrm{GHz})$. The fabricated planar horn antenna complemented by the aluminum transition between the equivalent SIW waveguide and the WR12 waveguide is shown in Fig. 8.

The reflection coefficient of the antenna prototype has been computed using CST Microwave Studio and measured in the $50-100 \mathrm{GHz}$ band. The agreement between simulation and measurement is very well observed, see Fig. 9. The antenna is well matched from $65 \mathrm{GHz}$ up to $100 \mathrm{GHz}$ and further.

The radiation patterns were measured only for top half-plane in an anechoic antenna chamber. Measurements were done at six frequencies for both planes. The gain was measured by the comparison method with a standard horn.

The comparison of measured and simulated radiation patterns in E-plane and H-plane at the center of both frequency bands $(73.5 \mathrm{GHz}$ and $83.5 \mathrm{GHz})$ are shown in Fig. 10 and Fig. 11. The simulated and measured data are in a good agreement except the part of the side lobes in Eplane. Their levels are about $3 \mathrm{~dB}$ higher in the worst case.
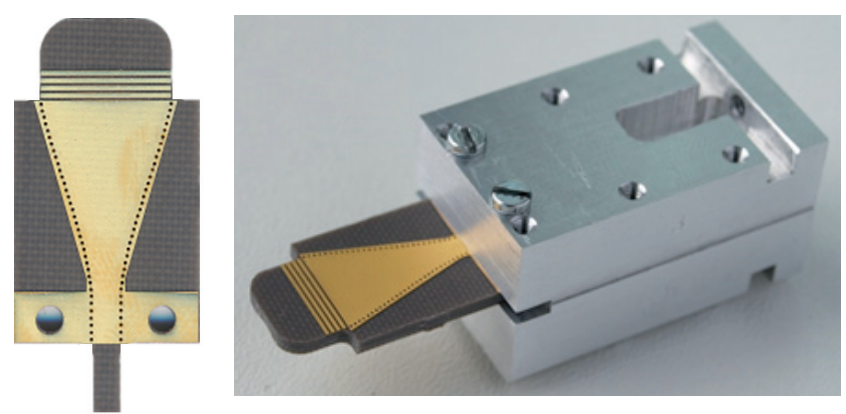

Fig. 8. Fabricated H-plane horn antenna with novel transition.

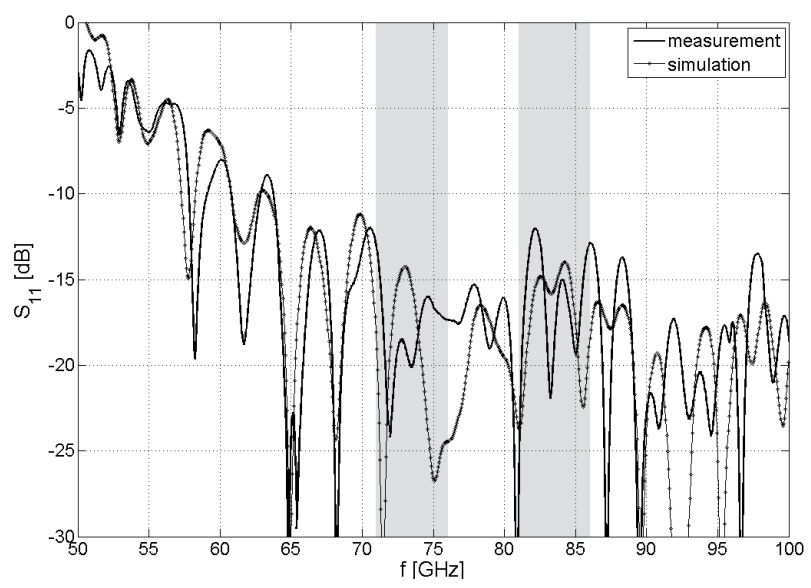

Fig. 9. The reflection coefficients of the SIW horn antenna with the transition.
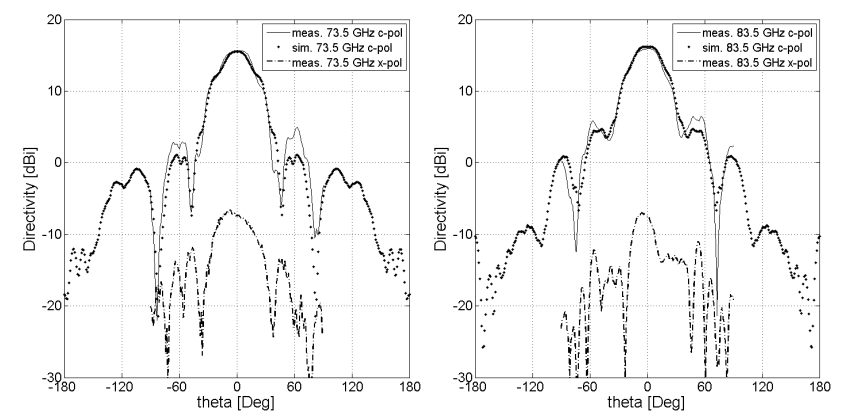

Fig. 10. Radiation patterns in E-plane: $73.5 \mathrm{GHz}$ (left); 83.5 GHz (right).
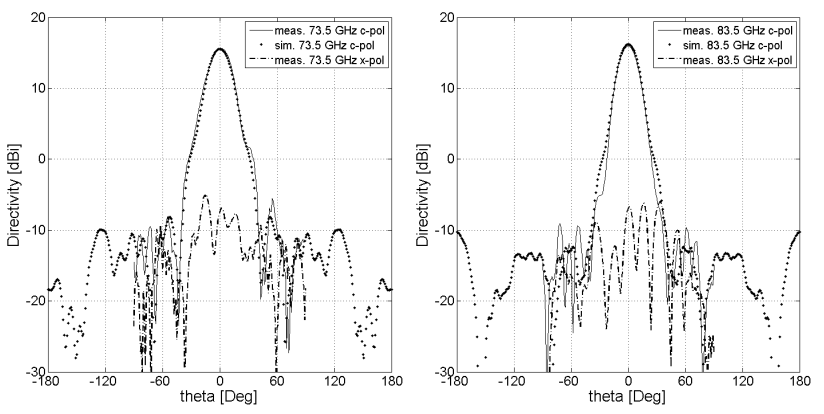

Fig. 11. Radiation patterns in H-plane: $73.5 \mathrm{GHz}$ (left); 83.5 GHz (right).

Obviously, the influence of the metallic transition is more noticeable than we expected. Further, the fabricated metallic transition was made wider than in Fig. 3 which affects the shape of the main beam and side lobe level compared to radiation patterns in Fig. 5 and 7.

The cross polarization in main radiation directions remains lower than $23 \mathrm{~dB}$. The maximum measured directivity equals $15.4 \mathrm{dBi}$ at $73.5 \mathrm{GHz}$ which is about $0.2 \mathrm{~dB}$ lower value compared to the simulated one and $15.9 \mathrm{dBi}$ at $83.5 \mathrm{GHz}$ (simulated one is $16.2 \mathrm{GHz}$ ). The measured radiation properties of the planar SIW horn antenna are summarized in Tab. 2.

\section{Comparison with a Conventional Metallic Horn Antenna}

A conventional metallic horn antenna was also designed to cover both operating bands.

The structure of the conventional metallic horn antenna is depicted in Fig. 12. The antenna includes the standard flange UG-387/U, the rectangular waveguide WR-12, and the flaring waveguide designed according to [1]. For a simpler fabrication, the antenna body was designed to consist of two identical parts which are fixed together by proper construction components. The antenna is of the following dimensions: $W_{a}=3.10 \mathrm{~mm}, W_{b}=1.55 \mathrm{~mm}$, $A=20.00 \mathrm{~mm}, \quad H_{w}=8.55 \mathrm{~mm}, \quad H=12.61 \mathrm{~mm}, \quad L_{h}=$ $13.02 \mathrm{~mm}, L_{w}=43.00 \mathrm{~mm}, L=47.00 \mathrm{~mm}, C=10.61 \mathrm{~mm}$, $D=15.62 \mathrm{~mm}$. The fabricated metallic horn antenna is shown in Fig. 13. 

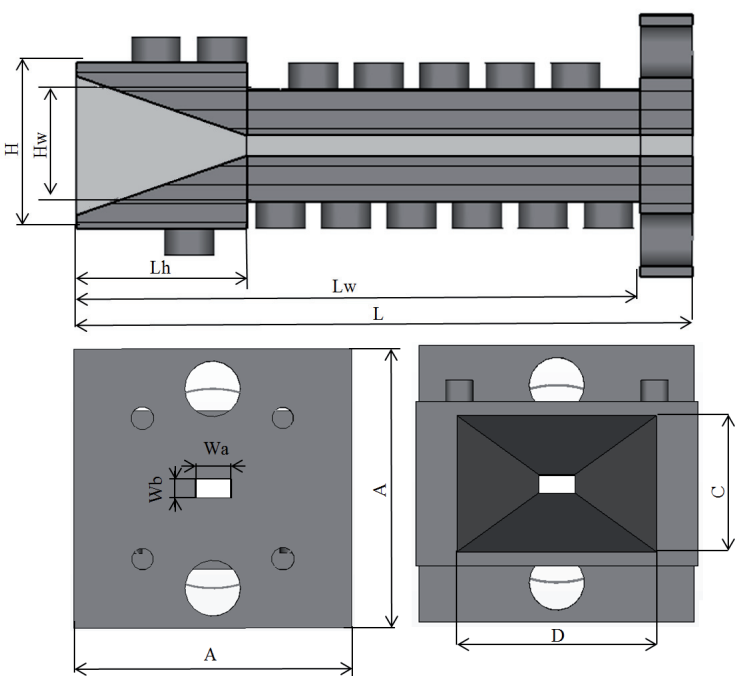

Fig. 12. Structure of the metallic horn antenna: side view (top); back and front view (bottom).

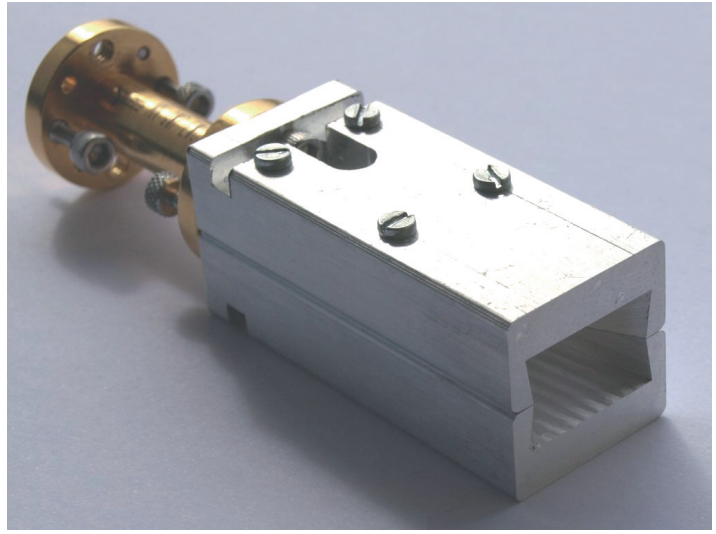

Fig. 13. Fabricated metallic horn antenna.

The measured reflection coefficients of both proposed antennas are compared in Fig. 14. The metallic horn antenna exhibits a better impedance matching within both the bands. However, the SIW horn antenna operates with the reflection coefficient lower than $-15 \mathrm{~dB}$ within the lower band and $-12 \mathrm{~dB}$ within the upper band which can be also considered as a good impedance matching.

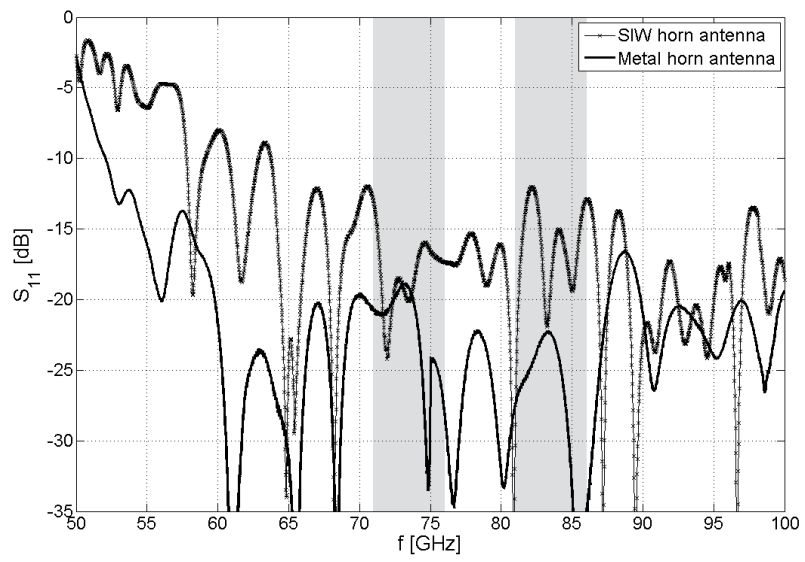

Fig. 14. Measured reflection coefficients of the metallic horn antenna and the planar SIW horn.
Figure 15 and 16 show the measured radiation patterns of the both antennas in the E-plane and the H-plane at several frequencies within the operation bands. The radiation pattern cuts of the SIW horn antenna indicate a wider beam (especially in E-plane) and worse suppression of the side lobes. The directivity is comparable with the metallic horn antenna. Further, the planar horn antenna has worse cross polarization parameters. Radiation properties are summarized in Tab. 2.
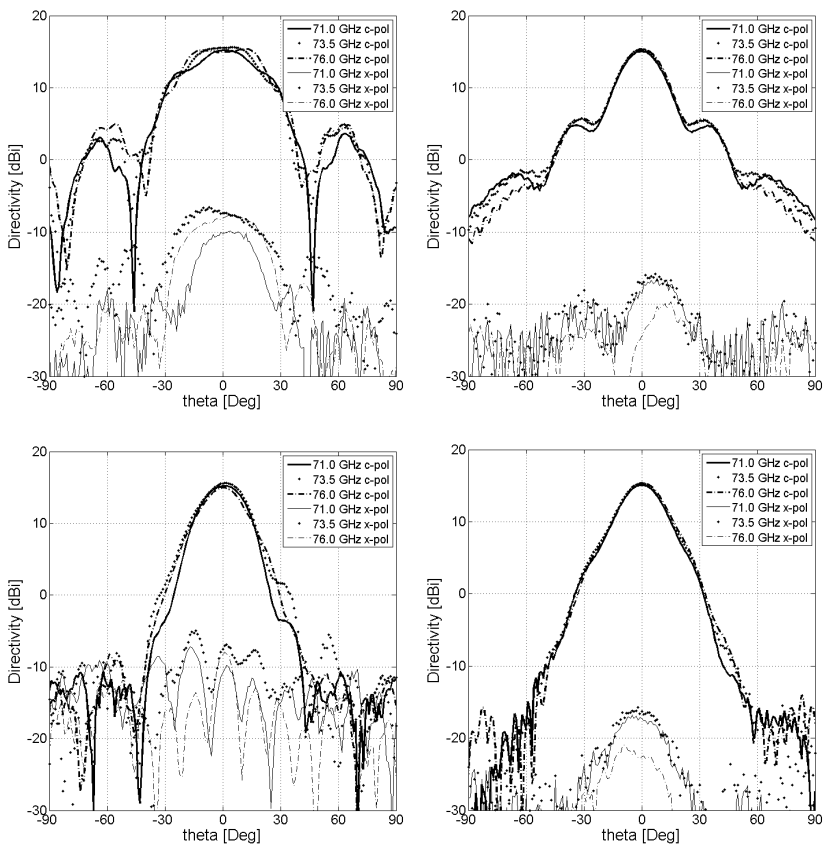

Fig. 15. Measured radiation patterns of the proposed horn antennas within the frequency band 71-76 GHz: E-plane (top); H-plane (bottom).
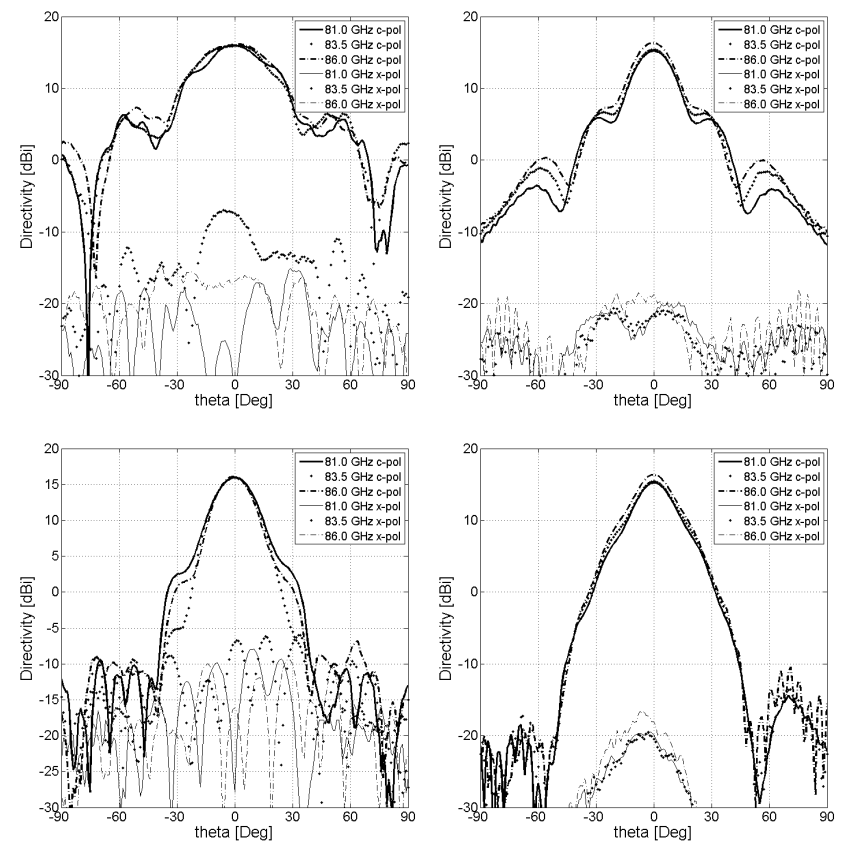

Fig. 16. Measured radiation patterns of the proposed horn antennas within the frequency band $81-86 \mathrm{GHz}$ : E-plane (top); H-plane (bottom). 
Nevertheless, the planar H-plane horn antenna excels in wideband impedance properties and higher gain in comparison with other planar antenna structures. Moreover the design of the antenna is relatively simple and requirements on the fabrication technology are not highly demanding.

\begin{tabular}{c|c|c|c|c}
\hline \multicolumn{2}{c|}{ Frequency (GHz) } & $\mathbf{7 1 . 0}$ & $\mathbf{7 3 . 5}$ & $\mathbf{7 6 . 0}$ \\
\hline \hline \multicolumn{2}{c|}{ Directivity (dBi) } & $15.1 / 15.2$ & $15.3 / 15.4$ & $15.4 / 15.3$ \\
\hline \multirow{2}{*}{ SLL (dB) } & plane E & $10.3 / 11.6$ & $9.8 / 10.8$ & $9.7 / 10.4$ \\
\cline { 2 - 5 } & plane H & $30.0 / 25.6$ & $30.5 / 21.1$ & $30.1 / 24.0$ \\
\hline \multirow{2}{*}{ BW (deg) } & plane $\mathbf{E}$ & $21.9 / 40.4$ & $22.2 / 43.5$ & $22.3 / 43.5$ \\
\cline { 2 - 5 } & plane H & $22.8 / 24.6$ & $22.5 / 25.6$ & $22.4 / 22.9$ \\
\hline \multirow{2}{*}{ Frequency (GHz) } & $\mathbf{8 1 . 0}$ & $\mathbf{8 3 . 5}$ & $\mathbf{8 6 . 0}$ \\
\hline \hline \multicolumn{2}{c}{ Directivity (dBi) } & $15.2 / 16.0$ & $15.4 / 15.9$ & $16.3 / 16.1$ \\
\hline \multirow{2}{*}{ SLL (dB) } & plane E & $9.3 / 9.8$ & $8.7 / 9.5$ & $16.0 / 8.9$ \\
\cline { 2 - 5 } & plane H & $29.7 / 25.6$ & $29.1 / 25.3$ & $28.0 / 23.1$ \\
\hline \multirow{2}{*}{ BW (deg) } & plane E & $20.4 / 36.0$ & $20.5 / 38.0$ & $20.8 / 40.2$ \\
\cline { 2 - 5 } & plane H & $20.3 / 20.7$ & $20.3 / 20.7$ & $20.2 / 18.9$ \\
\hline
\end{tabular}

Tab. 2. Comparison of radiation properties of the proposed antennas; metallic horn antenna/SIW horn antenna; ( $\mathrm{SLL}=$ side lobe level, BW = beam width).

\section{Conclusions}

In the paper, we described the design of horn antennas for an experimental 75/85 GHz wireless link. We developed the planar SIW H-plane horn antenna with the novel transition between the thin substrate and the air. The novel transition improves both the impedance matching and radiation parameters of the antenna. Directivity is improved more than $5 \mathrm{dBi}$ in comparison with other planar horn antenna structures.

The planar horn antenna was compared with the conventional metallic horn antenna. The metallic horn antenna exhibits slightly better impedance and radiation properties than the planar one. Nevertheless, fabrication of the planar horn antenna is much easier (PCB technology can be used). Both the conventional antenna and the SIW one exhibit the directivity more than $15 \mathrm{dBi}$. Even such low gain antennas ensure a satisfactory signal to noise ratio in wireless communication ranging up to $100 \mathrm{~m}$.

\section{Acknowledgments}

Research described in this paper was financed by the Czech Ministry of Education in frame of the National Sustainability Program under grant LO1401. For the research, infrastructure of the SIX Center was used.

\section{References}

[1] BALANIS, C. A. Antenna Theory: Analysis and Design. $3^{\text {rd }}$ ed. Hoboken (US-NJ), 2005, p. 739-810.
[2] LI, Z., CHEN, X.-P., WU, K. A surface mountable pyramidal horn antenna and transition to substrate integrated waveguide. In Proceedings of the International Symposium on Signals, Systems and Electronics (ISSSE). Montreal (Canada), February 2007, p. 607-610. DOI: 10.1109/ISSSE.2007.4294549

[3] WANG, H., FANG, D.-G., ZHANG, B., CHE, W.-Q. Dielectric loaded substrate integrated waveguide (SIW) H-plane horn antennas. IEEE Transactions on Antennas and Propagation, 2010, vol. 58, no. 3, p. 640-647. DOI: 10.1109/TAP.2009.2039298

[4] YOUSEFBEIKI, M., DOMENECH, A. A., MOSIG, J. R., FERNANDES, C. A. Ku-band dielectric-loaded SIW horn for vertically-polarized multisector antennas. In Proceedings of the 6th European Conference on Antennas and Propagation (EUCAP). Prague (Czech Republic), March 2012, p. 2367-2371. DOI: 10.1109/EuCAP.2012.6206106

[5] CHE, W., FU, B., YAO, P., CHOW, Y. L., YUNG, E. K. N. A compact substrate integrated waveguide H-plane horn antenna with dielectric arc lens: Research articles. International Journal of RF and Microwave Computer-Aided Engineering, Sep. 2007, vol. 17 , no. 5 , p. 473-479. DOI: $10.1002 /$ mmce. 20237

[6] ESQUIUS-MOROTE, M., FUCHS, B., ZURCHER, J., MOSIG, J. R. Novel thin and compact H-plane SIW horn antenna. IEEE Transactions on Antennas and Propagation, June 2013, vol. 61, no. 6, p. 2911-2920. DOI: 10.1109/TAP.2013.2254449

[7] Sivers IMA. FC1003E/03 81-86 GHz TX, 71-76/81-86 GHz RX Converter [online] Kista (Sweden): Sivers IMA AB, 2012. Cited 2013-20-8. Available at: http://www.siversima.com

[8] YAN, L., HONG, W., WU, K., CUI, T. J. Investigations on the propagation characteristics of the substrate integrated waveguide based on the method of lines. IEE Proceedings on Microwaves, Antennas and Propagation, 2005, vol. 152, no. 1, p. 35-42. DOI: 10.1049/ip-map:20040726

\section{About the Authors ...}

Jan BARTYZAL was born in the Czech Republic. He received his Ing. (M.Sc.) degree from the Air Military University, Košice, Slovakia, in 1988. He was the R\&D Director at TESLA Holding JSC.

Tomáš MIKULÁŠEK was born in the Czech Republic in 1985. He received his master's degree from the Faculty of Electrical Engineering and Communication (FEEC), Brno University of Technology (BUT), Czech Republic, in 2009. At present, he is a Post Doc at the Dept. of Radio Electronics, FEEC BUT.

Jan PUSKELY received the M.Sc. and Ph.D. degrees from the Brno University of Technology (BUT). At present, he occupies a post-doctoral position at the Dept. of Radio Electronics, Brno University of Technology. His research interest is focused on analysis and design of antennas, modeling and simulation of microwave and RF structures, antenna measurement and EMC.

Zbyněk RAIDA has graduated at Brno University of Technology, Faculty of Electrical Engineering and Communication (FEEC BUT). Since 1993, he has been with the Dept. of Radio Electronics FEEC BUT, now as a Professor. In 1996 and 1997, he was with the Laboratoire de Hyperfrequences, Universite Catholique de Louvain, Belgium, working on variational methods of numerical analysis of electromagnetic structures. In 2006-2013, he was the 
head of the Dept. of Radio Electronics, and since 2010 he has been the head of the SIX Center. Together with his students and colleagues, Zbyněk Raida has been working on numerical modeling and optimization of electromagnetic structures, exploitation of artificial neural networks for solving electromagnetic compatibility issues, and the design of special antennas. Zbyněk Raida is a member of IEEE Microwave Theory and Techniques Society.

Václav ̌̌ĚrICHA received the M.S. degree from the Czech Technical University in Prague in 1979. He is now working at Tesla a.s. Prague heading the Microwave Department. His research interests are related to the design of microwave circuits (both active and passive) and networks for radio links.

Tomáš URBANEC was born in Třinec, Czech Republic. He received his M.Sc. in 2000 and his Ph.D. in 2007, both from Brno University of Technology. Since 2007, he has been an assistant at the Department of Radio Electronics, BUT. He is interested in microwave measurement and design. 